\title{
108 FORE F00T AREA, LENGTH AND BREADTH OF FORE FOOT AS DETERMINANTS IN SPRINT AND LONG DISTANCE RUNNING
}

Rajasekhar Kali Venkata, Krishnamoorthy Dommalapati, ${ }^{2}$ Siva Kishore, ${ }^{1}$ Sarah Sarojini ${ }^{1}$ Centre for Physical Fitness and Sports Sciences, School of Medical Sciences, University of Hyderabad, Hyderabad, Andhra Pradesh, India; ${ }^{2}$ Department of Physical Education, Sri Venkateswara University, Tirupati, Andhra Pradesh, India; ${ }^{3}$ Department of Physical Education, Sri Padmavathi Mahila University, Tirupati, Andhra Pradesh, India

\subsection{6/bjsm.2010.078725.108}

Higher metabolic cost of propulsion leads to quicker depletion of muscle phosphagens and accumulation of lactic acid while sprinting and uneconomical metabolic cost leading to quicker fatigue while running long distances. Larger foot dimensions need more propulsive force. This study analysed correlation among the forefoot area, length and breadth of forefoot and maintenance of top sprinting speed and distance running capacity of individuals. Timings for last $40 \mathrm{~m}$ in $100 \mathrm{~m}$ run to understand sprint maintenance and $1500 \mathrm{~m}$ to understand distance run were correlated. Foot area of the subjects was measured by graph weighing method. Zero, first and second order partial correlations were applied to analyse results. Significant zero order positive correlations were found between foot area and sprint maintenance $(r=0.355)$ and distance running $(r=0.225)$ at 0.05 level of significance. The positive correlations between fore foot area and the sprint maintenance timing $\left(r_{2}\right.$ $=0.336)$ and fore foot area and distance running timing $\left(r_{2}=\right.$ 0.213 ) were significant (at df 200; $r=0.132$ ) when the effect of fore foot length and breadth were removed by second order correlation. First order correlations also were significant between forefoot area and sprint maintenance $\left(r_{1}=0.345\right.$ and $r_{1}=0.336$, length and breadth effect removed, respectively) and distance running $\left(r_{1}=0.224\right.$ and $r_{1}=0.213$, respectively). It appears the sprint maintenance ability during the last $40 \mathrm{~m}$ of $100 \mathrm{~m}$ and distance running capacity decreases with the increase in the area of the fore foot. 